\title{
Association between atherosclerosis and osteoporosis, the role of vitamin D
}

Olivera Ilić Stojanovic ${ }^{1}$, Milica Lazovic ${ }^{1}$, Marko Lazovic ${ }^{2}$, Marina Vuceljic ${ }^{3}$

\author{
${ }^{1}$ Institute of Rehabilitation, Belgrade, Serbia \\ ${ }^{2}$ Clinic for Cardiovascular Diseases, Clinical Center Niš, Belgrade, Serbia \\ ${ }^{3}$ Biochemical Laboratory ALLABO, Belgrade, Serbia
}

Submitted: 15 December 2010

Accepted: 2 March 2011

Arch Med Sci 2011; 7, 2: 179-188

DOI: 10.5114/aoms.2011.22066

Copyright (c) 2011 Termedia \& Banach

\section{Abstract}

The latest data support the correlation of atherosclerosis and osteoporosis, indicating the parallel progression of two tissue destruction processes with increased fatal and non-fatal coronary events, as well as higher fracture risk. Vitamin D inadequacy associated with low bone mineral density increases fall and fracture risk, leads to secondary hyperparathyroidism, calcifies coronary arteries and significantly increases cardiovascular disease. Randomized clinical trial evidence related to extraskeletal vitamin D outcomes was limited and generally uninformative. A recent recommendation on vitamin $D$ dietary requirements for bone health is $600 \mathrm{IU} / \mathrm{d}$ for ages $1-70$ years and $800 \mathrm{IU} / \mathrm{d}$ for 71 years and older, corresponding to a serum 25-hydroxyvitamin D level of at least $20 \mathrm{ng} / \mathrm{ml}$ (50 nmol/l). Further large randomized controlled trials are needed to reassess laboratory ranges for 25 -hydroxyvitamin $D$ in both diseases, in order to avoid under- and over-treatment problems, and completely clarify the relationship between atherosclerosis and osteoporosis.

Key words: vitamin D deficiency, low bone density, cardiovascular disease, fracture risk.

\section{Introduction}

Both epidemiological and clinical studies have indicated that patients with low bone mineral density (BMD) are at significantly greater risk of developing cardiovascular disease (CVD) as well as unexpected cardiovascular events, more severe coronary atherosclerosis and vascular calcification [1-4].

Pathophysiological mechanisms that connect atherosclerosis and osteoporosis (OP) are complex and could be dependent and/or independent of the production of vitamin D (Vit D). A low level of Vit D decreases BMD, influences neuromuscular dysfunction (weakness of proximal muscles), increases the risk of falls and fractures, and stimulates the renin-angiotensin system, leading to the development of hypertension (HTA), left ventricular hypertrophy, and coronary artery calcification associated with congestive heart failure [5].

A recent review of randomized trials evaluating the effect of greater doses and higher achieved 25-dihydroxyvitamin D [25(OH)D] levels on health outcomes concluded that the optimal benefit of Vit D for CVD (as well as cancer) was obtained at $25(\mathrm{OH}) \mathrm{D}$ concentrations of $75-110 \mathrm{nmol} / \mathrm{l}$ (30-44 ng/ml). These levels can best be obtained with oral daily doses of Vit D in the range of 1,800 to $4,000 \mathrm{IU}$ [6]. 


\section{Cardiovascular disease and osteoporosis}

At present, growing evidence indicates the existence of a correlation between CVD and OP (fractures), irrespective of age [1-3]. These clinical conditions, linked by numerous common pathophysiological mechanisms and risk factors, are asymptomatic in the early clinical stages. It is a fact that 200 million people have been diagnosed with $\mathrm{OP}$, whereas epidemiological studies concerning the number of atherosclerosis sufferers do not exist. The socio-economic consequences of both these diseases are very important bearing in mind the facts that OP is the second highest world health problem after CVD, and this number will increase with the growth of the elderly population over the next decades.

Cardiovascular disease and OP together account for most of the morbidity and mortality in our aging population despite significant improvements in treatment. Osteoporotic postmenopausal women are at significantly greater risk of CVD, cardiovascular mortality and bone fractures than agematched controls $[4,5]$. Patients with lower bone density and OP also have higher lipid levels, more severe coronary atherosclerosis, and a greater risk of stroke death. The common finding of simultaneous vascular calcification and OP in individual patients suggests that local tissue factors govern the regulation of biomineralization [7]. Serum 25(OH)D levels are inversely associated with important CVD risk factors. The latest results indicate a strong and independent relationship of $25(\mathrm{OH}) \mathrm{D}$ deficiency with prevalent CVD in a large representative sample of the US adult population [8].

The following facts clearly reflect the association between these two diseases. Risk factors for vascular disease, such as dyslipidaemia, systemic arterial HTA, diabetes mellitus, and hyperhomocysteinaemia, have been associated with a higher incidence of low bone mineral density. In addition, there is evidence indicating the action of antiresorptive drugs on the reduction of cardiovascular risks and the effect of statins, antihypertensives and insulin on bone mass increase [1]. The connection between low values of $B M D$ and the risk of fractures is similar to the correlation between HTA and cardiovascular events. It has been established that myocardial infarction is the cause of approximately $50 \%$ of all fatalities.

\section{Fracture and pain assessment in osteoporotic patients}

A myocardial infarction is often the first clinical manifestation of atherosclerosis, as well as fractures in patients with low BMD. Pain is the first clinical manifestation of OP and atherosclerosis. It can be seen that $30-40 \%$ of women aged over 50 years have low BMD and coronary disease, with the prevalence of carotid atherosclerosis of $42 \%$ in the observed population [9]. Of all postmenopausal women, $30 \%$ have OP of the hip, lumbosacral spine (LS), or in the distal segment of the radius [10]. More than $50 \%$ have had a previously diagnosed fracture of the proximal part of the femur, vertebral fracture, proximal part of the humerus, a distal segment of the forearm or of the pelvis [10]. With regard to the latest scientific knowledge, reference values of BMD for men have been shown to be on the same level of fracture risk as amongst women, which can also be linked to the risk of coronary diseases in both genders [11].

In OP, pain is a consequence of a low energy fracture or spontaneous fracture which points to late diagnosis. It is a remarkable fact that about $50 \%$ of women aged over 50 years had no idea they were suffering from vertebral fractures. Therefore, it is of particular importance for everyday clinical practice to recognise them early, because the intensity of pain is not in correlation with the presence and degree of vertebral fracture, and often is not linked with a known mechanical load. Moreover, some of these women felt no pain at all. Indeed, only $33 \%$ of vertebral fractures are considered to be diagnosed in clinical practice. On the other hand, not all patients suffer an OP diagnosed fracture during their lives, but 30-40\% of patients with osteopenia had fractures as well as $10-20 \%$ of patients with a T-score within the range of reference values [10]. Fracture risk reduction correlates neither with the degree of raised $B M D$ nor with the same $B M D$ in relation to various geographical areas. Until recently it was considered that $70-80 \%$ of fractures were determined by BMD. Now, it is known that BMD, by around $30 \%$, Not clear is one among a number of risk factors in the assessment of bone quality and fracture risk. Genetic factors, however, dominate all risk factors by over $60 \%$. This position is supported by a cohort study which investigated the frequency of fractures in OP. Only $46 \%$ of women with fractures had BMD in the OP level [12]. The incidence of typical fractures in OP is low and varies in different fracture locations over a wide spectrum ranging from less than $10 \%$ to $44 \%$ [13]. Moreover, cases with a T-score within the level of OP at one measurement point do not have to have OP anywhere else. Therefore, a large number of measurement points raises the probability of better assessing fracture risk, as concluded in some published articles [11, 14].

In the latest recommendations regarding evaluation for initiating therapy, great importance is given to assessing future fracture risk (Frax algorithm) estimated over 10 years 
(www.shef.ac.uk./FRAX) using previous X-ray evaluations for fractures of the vertebral column, and BMD [15].

\section{Association of atherosclerotic processes with bone metabolism and osteoporosis}

The effect of atherosclerosis on bone metabolism and the development of OP was established owing to investigations confirming that a decreased value of BMD is a good mortality predictor during cardiovascular occurrences and coronary disease in postmenopausal women and men older than 50 years of age. In fact, the connection between CVD and OP exists not only in the process of aging. A connection has been confirmed between the decreased value of BMD, and unexpected cardiovascular mortality, as well as the incidence of CVD occurring in Caucasian women, but not in men $[3,4]$.

A correlation exists between OP and atherosclerosis regardless of age, body mass index (BMI) and cardiovascular risks. Cases of low BMD of the hip have a higher risk of CVD mortality in both genders [16].

The inverse correlation of cardiovascular calcification and loss of bone calcium indicates that this is the parallel progression of two processes of tissue destruction. Postmenopausal women with atherosclerotic changes of the abdominal aorta, in comparison with those having no vascular calcification, have a significantly decreased value of $B M D$ at the lumbar spine and hip, higher hip fracture risk $(\times 2.9)$ and vertebral fracture risk $(\times 4.8)$, as well as a higher incidence of fatal and non-fatal coronary events [17].

Pathophysiological mechanisms connecting atherosclerosis and osteoporosis are complex and can be dependent or independent of the production of vitamin D. Hyperproduction of inflammatory markers such as C-reactive protein, interleukin-1 (IL-1), interleukin-6 (IL-6) and tumour necrosis factor- $\alpha$ (TNF- $\alpha$ ) can be considered risk factors and some are directly related to the severity of atherosclerosis, with pre-resorption effects and the stimulation of osteoclastogenesis [1].

\section{Association of lipid fraction levels with osteoblast and osteoclast function}

An increase of low density lipoprotein cholesterol (LDL-C) and a reduction of high density lipoprotein cholesterol (HDL-C) levels have been associated with low BMD in postmenopausal women [18].

Lipid oxidation products such as minimally oxidized LDL-C promote arterial calcification, and its accumulation in the subendothelial space of skeletal bone arteries inhibits bone formation [19]. The hyperproduction of oxidized low density lipoprotein fraction of cholesterol stimulates atherogenesis and activates osteoblasts in the arterial pool, leading to the calcification of arterial plaque. However, the published results are controversial. It has been shown that plasma LDL-C level inversely correlated with BMD values, while low plasma triglyceride (TG) levels were associated with the presence of vertebral fractures in postmenopausal women [18-22].

Some studies found no association between serum lipid concentrations and BMD [23] and other studies found even a positive relationship between them [22-25].

The study of Sivas et al. [22] showed that serum lipids have an impact on vertebral fracture existence, rather than BMD alterations. The total cholesterol (TC), TG and LDL-C levels were lower in postmenopausal women who had at least one vertebral fracture. TC level was the strongest factor affecting vertebral fracture existence. And an increase of $1 \mathrm{mg} / \mathrm{dl}$ TC decreased the risk of vertebral fracture by $2.2 \%$. In the study of Jeong et al. [26] after adjustment for clinical and laboratory covariates, the authors found a weak positive association between HDL-C and BMD at the lumbar spine only in postmenopausal women. This result is in accordance with the work of Yamaguchi et al. [18] but opposite to the results of the study by Adami et al. [24], in which worse lipid profiles (lower HDL-C and higher LDL-C or TG) were associated with higher bone mass, although they could not provide a documented explanation. In conclusion, the correlation between lipid profile and BMD was neither consistent at all bone sites [26], nor from study to study. Further studies are needed to clarify this relationship and the underlying mechanism.

The artery wall contains endothelial cells capable of differentiation into osteoblasts, following the same stages of differentiation as occur in bonederived osteoblasts, and ultimately producing bone mineral. So, the same oxidized lipids that induce atherosclerosis also induce mineralization and differentiation of the osteoblastic cells in the artery wall. Consistent with this finding, hyperlipidaemia is associated with vascular calcification in mice [7]. On the other hand, hyperproduction of LDL-C and lipid accumulation in the subendothelial matrix would be expected to inhibit differentiation of osteoblasts from preosteoblasts and enhance osteoclastic differentiation and activity, which lead to decreased bone density. Oxidized lipids induce endothelial expression of monocyte chemotactic factors and the monocyte colony-stimulating factor (M-CSF), a potent inducer of osteoclastic differentiation and differentiation of osteoclast precursor cells, which consequently promote bone resorption $[18,19]$. At the same time, oxidized LDL-C molecules act in the suppression of terminal 
differentiation of stromal cells into osteoblasts, while HDL inhibits cytokines responsible for the osteogenic differentiation of vascular cells [27]. The mechanism of arterial calcification resembles the process of osteogenesis, involving various cells, proteins and cytokines that lead to tissue mineralization [28]. Clinical studies also support the role of lipids in both vascular calcification and OP. Lipid-lowering agents reduce coronary vascular calcification in patients, where the degree of improvement follows in direct relation to the degree of lowered lipids [29]. Lipid-lowering agents also enhance bone mineralization in rodents [30] and humans [31] and may reduce the incidence of osteoporotic fractures in patients [32-34]. These effects on bone were originally attributed to a direct effect of the specific class of lipid-lowering agents used, hydroxymethylglutaryl-coenzyme $A$ (HMG-CoA) reductase inhibitors (statins). It is possible that statins may directly protect bone [20]. However, it is not yet possible to distinguish whether the improvement in bone density and reduction in fracture risk are due to lipid lowering or to a direct effect of statins on bones. It is notable that bisphosphonates, leading agents for $O P$, also reduce LDL cholesterol and increase HDL cholesterol levels in humans [35]. Experimental studies using animal models of vascular calcification have demonstrated that bisphosphonates completely inhibit arterial and cardiac calcification in mice [36]. The protective effect of bisphosphonates has been attributed to their direct action on the vessel wall by sensitizing macrophages to undergo apoptosis, preventing foam cell formation by inhibiting the uptake of LDL-C and affecting cell replication [37]. Also, a recent study showed that bisphosphonates induce inflammation and rupture of atherosclerotic plaques in apolipoprotein-E null mice [38]. These data support the concept that lipids contribute to both vascular calcification and OP. Osteopenia and OP correlate positively with atherosclerosis, vascular calcification, and cardiovascular events, with some evidence of age independence [3]. Thus, plasma lipids may be related to bone mass and bone fragility, and could be the common factor underlying both OP and vascular calcification, which suggests that these diseases share common pathophysiological pathways [27]. In human calcified atherosclerotic plaque, as in bone tissue, the same modulators of bone metabolism can be detected: osteopontin (OPN), osteocalcin, matrix Gla protein (MGP), osteonectin, osteoprotegerin $(\mathrm{OPG})$, bone morphogenetic protein (BMP), receptor activator of nuclear factor $\kappa \mathrm{B}$ ligand (RANKL), inflammatory cytokines, type 1 collagen, proteoglycan and nitric oxide (NO). The dysfunction of endothelial synthase (e-NOS) of NO is present in both processes $[18,39,40]$. Several mechanisms of vascular injury have been proposed for homocysteine, including a reduction in nitric oxide, endothelial dysfunction, increased platelet aggregation, and proliferation of vascular smooth muscle cells, among others [27].

Furthermore, bone and coronary arteries are target organs for oestrogens. Vitamin D directly affects oestrogen synthesis by regulating the activity of aromatase in osteoblasts [41] and oestrogen half-life by regulating 17 hydroxysteroid dehydrogenase in keratocytes [42]. Woman after the menopause demonstrate accelerated bone loss. Also, the beneficial effects of oestrogens on the cardiovascular system and atherosclerosis are well established [19, 43, 44].

Homocysteine is a possible risk factor for atherosclerosis [45]. Homocystinuria is a genetically inherited disease which is characterised by elevated plasma homocysteine concentrations. Its clinical manifestations, apart from skeletal disorders and $\mathrm{OP}$, include a tendency towards premature atherosclerosis and thromboembolism. There is also evidence that postmenopausal woman with a heterozygous mutation in methylenetetrahydrofolate reductase (MTHFR) and, therefore, hyperhomocysteinaemia demonstrate a decrease in BMD. This supports the hypothesis that homocysteine participates in the interaction between oestrogen and bone metabolism $[19,46]$.

Also patients with OP and atherosclerosis exhibit insufficient vitamin K levels. Vitamin $\mathrm{K}$ is a cofactor required to convert the amino acid glutamate into gamma-carboxyglutamate, or Gla-proteins [47]. Glaproteins regulate physiological processes controlled by calcium. These include blood coagulation (clotting) and bone mineralization. Accordingly, Glaproteins are critical to the formation and replenishment of bone tissue. Unless these proteins are modified by vitamin K, they cannot properly form the matrix in which calcium and phosphorus bind together to make solid, well-mineralized bone. Vitamin $\mathrm{K}$ has been shown to stimulate new bone formation and reduce the incidence of vertebral fractures [48, 49]. The Gla-protein osteocalcin, normally present in bone, has been found in calcified atherosclerotic plaque lesions, and production of this protein is pathologically upregulated in people with atherosclerosis [50]. At the same time, another vitamin K-dependent Glaprotein known as matrix Gla-protein (MGP), normally found in healthy arterial walls, is a strong inhibitor of vascular calcification [51, 52]. In other words, by increasing MGP in the arterial walls, vitamin $\mathrm{K}$ protects against the calcification-inducing effects of osteocalcin. Therefore, vitamin $\mathrm{K}$ deficiency is also a confounder in the OP/CVD relationship. 


\section{Potential pathophysiological mechanisms which determine the role of vitamin $D$ in atherosclerosis and osteoporosis}

Except for the association of Vit $D$ deficiency with the prevalence of traditional CVD risk factors, emerging data suggest a more direct role of Vit $D$ in the development of atherosclerotic disease [53].

Several pathophysiological mechanisms which determine the role of Vit $D$ in atherosclerosis/cardiovascular disease and OP have been proposed and are summarised in Table I.

Serum concentration of $25(\mathrm{OH}) \mathrm{D}$, the main circulatory metabolite of Vit D, was accepted in 1997 by the Panel on Calcium and Related Nutrients of the Food and Nutrition Board (IOM-NAS) as a barometer for the status of Vit D. 25-hydroxyvitamin D, as a substrate of renal and extra-renal production of 1,25-dihydroxyvitamin $D$, reflects the total production (endogenous and exogenous sources) of Vit D. The presence of the physiological active metabolite $1,25(\mathrm{OH})_{2} \mathrm{D}$ - 1,25 dihydroxyvitamin $D_{3}$ shows that Vit $D$ has a hormonal effect. Vitamin $D$ receptors (VDR) are present in many different tissues, such as brain, breast, immune cells, muscle tissue, parathyroid glands, cardiomyocytes, vascular endothelial and vascular smooth muscle cells, endothelial cells of colon mucosae, as well as malignant colon cells $[54,55]$.
The expression of VDR in vascular endothelial and smooth muscle cells converts $25-\mathrm{OH}$ Vit D from a biologically inactive form (in a physiological concentration) by hydroxylation in the kidneys of 1 - $\alpha$ hydroxylase into $1,25(\mathrm{OH})_{2} \mathrm{D}$ (dihydroxycholecalciferol), the active metabolic form of Vit $D$, regulated by parathyroid hormone (PTH) secretion. Dihydroxycholecalciferol regulates the reninangiotensin axis by directly suppressing the renin gene. 25(OH)D binds with Vit D binding protein (DBP) and is transported to the kidneys through the circulation [54].

Kidney activity may decrease during ageing, parallel with decreased renal function, and a similar decrease in DBP, as well as a lessening of albumin in sera. Subsequently, low levels of 25(OH)D in older people with hip fractures may be a consequence of decreased DBP as the active metabolites of Vit D are mainly linked to DBP.

An inadequacy of Vit $D$ directly promotes the development of HTA, leads to the hyperproduction of PTH and, consequently, secondary hyperparathyroidism, cardiomyocyte hypertrophy and vascular remodelling - ventricular hypertrophy. Also, this process influences inflammation by stimulating the release of cytokines from smooth muscle vascular cells [56]. Vitamin D inhibits vascular calcification by blocking the release of inflammatory

Table I. Potential pathophysiological mechanisms of vitamin D in atherosclerosis/cardiovascular disease and osteoporosis

\begin{tabular}{|c|c|}
\hline Atherosclerosis/cardiovascular disease & Osteoporosis \\
\hline $\begin{array}{l}\text { - VDR polymorphisms (especially Bsml) } \\
\text { - Presence of } \alpha \text {-hydroxylase enzyme in endothelium } \\
\text { - Presence of VDRs in endothelium and VSMC } \\
\text { - PTH suppression } \\
\text { - Regulation of renin-angiotensin-aldosterone system } \\
\text { - Presence of VDRs in immune cells (T-lymphocytes, } \\
\text { macrophages) } \\
\text { - Downregulation in the production of inflammatory } \\
\text { markers (CRP) and several cytokines (IL-1, IL-2, IL-6, } \\
\text { IL-12, interferon- } \gamma \text {, TNF- } \alpha \text {, TNF- } \beta \text { ) } \\
\text { - Suppression of EGF in VSMC } \\
\text { - Induction of prostacyclin in VSMC } \\
\text { - Downregulation of PAI-1, thrombospondin-1 } \\
\text { and thrombomodulin } \\
\text { - Suppression of foam cell formation } \\
\text { - Reduced gene expression of bone-forming cells } \\
\text { in the aorta }\end{array}$ & $\begin{array}{l}\text { - VDR polymorphisms } \\
\text { - Decline in renal } 1,25(\mathrm{OH})_{2} \text { D production } \\
\text { - Regulation of PTH secretion } \\
\text { - Decline in intestinal VDR } \\
\text { - Decline in DBP } \\
\text { - Diminished renal response to PTH and reduced } \\
\text { intestinal calcium absorption } \\
\text { - Presence of VDRs in immune cells } \\
\text { (T-lymphocytes, macrophages) } \\
\text { - Downregulation in the production of inflammatory } \\
\text { markers and several cytokines } \\
\text { - Effect on oestrogen synthesis: } \\
\text { - regulating the activity of aromatase in osteoblasts, } \\
\text { - regulating } 17 \text { hydroxysteroid dehydrogenase }\end{array}$ \\
\hline
\end{tabular}

VSMC - vascular smooth muscle cells, VDR - vitamin D receptor, PTH - parathyroid hormone, CRP - C-reactive protein, IL - interleukin, $T N F$ - tumour necrosis factor, EGF - epidermal growth factor, PAl-1 - plasminogen activator inhibitor-1, VDR - Vit D receptor, DBP - Vit D binding protein, $1,25(\mathrm{OH})_{2} \mathrm{D}$ - dihydroxycholecalciferol

Adapted from: Anagnostis $P$, Athyros VG, Admidou F, Florentin M, Karagiannis A. Vitamin D and cardiovascular disease: a novel agent for reducing cardiovascular risk? Curr Vasc Pharmacol 2010; 8: 720-30 
cytokines and adhesion molecules and preventing abnormal changes in smooth muscle cells in vessel walls [57]. Accordingly, low vitamin D levels are associated with increased risk for development of the coronary arterial calcifications seen in atherosclerosis [58].

An inadequacy of Vit $D$ in serum decreases the absorption of calcium (Ca) in the intestine, causes low values of serum $\mathrm{Ca}$ and compensatory hypersecretion of PTH and $1,25(\mathrm{OH})_{2}$. This results in mobilising $\mathrm{Ca}$ and phosphorous (P) from bones, in order to maintain the optimal level of $\mathrm{Ca}$ and $\mathrm{P}$ in sera for bone turnover, metabolic processes and neuromuscular functions. Nevertheless, as a result of the compensatory mechanisms a serum level of $25(\mathrm{OH}) \mathrm{D}$ may be maintained at reference values despite hypocalcaemia [59]. The disturbance of homeostatic mechanisms influences both skeletal and extraskeletal metabolic processes. An inadequacy of Vit D lowers BMD, gives rise to neuromuscular dysfunction - proximal muscular weakness myopathy, sarcopenia, and increased risk of falls, although these are reversible processes [56].

Reduced levels of Vit D have a negative effect on the musculoskeletal system and, by increasing susceptibility to arterial calcification, cause an excess of cardiovascular risk factors. Clinical studies confirm that Vit D deficiency influences the activity of renin in plasma, which leads to HTA - via increased arterial resistance, calcification of the coronary arteries and a significant rise in CVD [60].

Vitamin $D$ regulation of renin expression was independent of calcium metabolism and $1,25(\mathrm{OH})_{2} \mathrm{D}_{3}$ markedly suppressed renin transcription by a VDR-mediated mechanism in cell cultures. Hence, $1.25(\mathrm{OH})_{2} \mathrm{D}_{3}$ is a novel negative endocrine regulator of the renin-angiotensin system. Its apparent critical role in electrolytes, volume, and blood pressure homeostasis suggests that Vit $D$ analogues could help prevent or ameliorate HTA [57].

Vitamin $D$ deficiency is associated with congestive heart failure and blood levels of inflammatory factors, including C-reactive protein and cytokines such as interleukin-10. Cytokines have recently been identified as having an important role in atherogenesis [61]. Vitamin D analogues have been shown to inhibit the production of several proinflammatory cytokines while stimulating the effects of Th2 lymphocytes, leading to a reduction in matrix metalloproteinase and, thereby, reducing plaque production or instability [62].

Secondary hyperparathyroidism, as a consequence of Vit D insufficiency, also has negative implications for the cardiovascular system and bone metabolism. Living at higher latitudes increases the risk of HTA, CVD and prevalence of Vit D insufficiency [63].
Recent evidence suggests that Vit D intakes above current recommendations may be associated with better health outcomes. However, optimal serum concentrations of $25(\mathrm{OH}) \mathrm{D}$ for skeletal and extraskeletal functions are different in various published investigations. Nevertheless, it can be concluded that a daily dose of 400 IU of Vit D does not adequately reduce fracture risk [64].

A review by Roux et al. [64] applied the risk assessment method used by the Food and Nutrition Board to update the safe tolerable upper intake level (UL). For Vit D the method focuses on the risk of hypercalcaemia. The last statement concerning the upper limit (UL) indicates the level above which there is risk of adverse events. The UL is not intended as a target intake; rather, the risk for harm begins to increase once intakes surpass this level [65].

In previous reviews the general conclusion was that the UL for Vit D consumption by adults should be $10000 \mathrm{lU} / \mathrm{d}$ [66]. This indicates that the margin of safety for Vit D consumption for adults is $>10$ times any current recommended intake [67]. The 1997 UL for Vit D was 2000 IU/d for most age groups. The starting point for the current UL for vitamin D was 10,000 IU/d, because lower intakes have been linked to neither hypercalcaemia nor acute toxicity. However, this value was corrected due to uncertainty, given that toxicity is not the appropriate basis for a UL that is intended to reflect long-term chronic intake and be used for public health purposes. The correction was based on chronic disease outcomes and all-cause mortality, as well as emerging concerns about risks at serum 25(OH)D levels above $50 \mathrm{ng} / \mathrm{ml}(125 \mathrm{nmol} / \mathrm{l})$. Thus, the Committee followed an approach to maximize public health protection and the UL for Vit $D$ is now $4000 \mathrm{IU} / \mathrm{d}[65]$.

For all endpoints, the most advantageous serum concentrations of $25(\mathrm{OH}) \mathrm{D}$ begin at $75 \mathrm{nmol} / \mathrm{l}$ $(30 \mathrm{ng} / \mathrm{ml})$, with the best being between $90 \mathrm{nmol} / \mathrm{l}$ and $100 \mathrm{nmol} / \mathrm{l}(36-40 \mathrm{ng} / \mathrm{ml})$. In most people, these concentrations cannot be reached with the currently recommended daily intakes of $200 \mathrm{IU}$ and 600 IU Vit D for younger and older adults, respectively. Several studies suggest that many older people will not achieve optimal serum $25(\mathrm{OH}) \mathrm{D}$ concentrations during the summer months, which suggests that Vit D supplementation should be independent of season in older persons [68]. An intake for all adults of $\geq 1000$ IU $(25 \mu \mathrm{g})$ Vit $D_{3}$ (cholecalciferol)/daily is needed to bring Vit D concentrations up to $75 \mathrm{nmol} / \mathrm{l}(30 \mathrm{ng} / \mathrm{ml})$ in at least $50 \%$ of the population [69]. An exploratory analysis of the heterogeneity demonstrated a significant positive association comparable to an increase of 1-2 nmol// in serum 25(OH)D for every 100 additional units of Vit $D$ although heterogeneity remained after adjusting for dose [70]. 
A reduction of risk of falls and fractures, without adverse effects, was proved for the dose 700-1000 IU with Ca supplementation (1000-1200 mg elementary Ca daily) [71]. This dose of Vit $D$ has an antiinflammatory effect and blocks plaque calcification in arterial blood flow. Toxic doses lead to medicalcinosis, which is a reversible process [57].

Furthermore, calcium supplementation by itself did not reduce risk of fractures [72]. As noted in the Institute of Medicine (IOM) review [65], in the analysis of NHANES data with more than 9,000 subjects, calcium intake was associated with hip bone density only among women with low 25(OH)D levels; in all other groups there was no relation between calcium intake and bone density. In contrast, $25(\mathrm{OH}) \mathrm{D}$ levels were consistently and positively associated with hip bone density [73]. Thus, with adequate $25(\mathrm{OH}) \mathrm{D}$ levels or sufficient Vit D intake, higher calcium intakes may not be correlated with bone health. In sum, calcium recommendations could be adjusted downward with Vit D supplementation; they could also possibly be adjusted downward for safety reasons. The IOM states that more data regarding the interaction of Vit $D$ and calcium on bone health are needed and no recommendation was provided on their combination [74].

In other studies it was found that the level of 25(OH)D below $30 \mathrm{ng} / \mathrm{ml}(75 \mathrm{nmol} / \mathrm{l})$ was strongly associated with suboptimal $\mathrm{Ca}$ absorption. A reduction of fracture incidence was observed when the level of $25(\mathrm{OH}) \mathrm{D}$ was above $75 \mathrm{nmol} / \mathrm{l}$ as, due to the beneficial effect on bone metabolism and muscle strength, there was a resulting lower incidence in the number of falls [75]. Also, it was noted that when the level of $25(\mathrm{OH}) \mathrm{D}$ was in the range $27.5-37.5 \mathrm{nmol} / \mathrm{l}$, the $\mathrm{PTH}$ level progressively rose [7].

In patients with HTA and a value of $25(\mathrm{OH}) \mathrm{D}$ $<27.5 \mathrm{nmol} / \mathrm{l}(15 \mathrm{ng} / \mathrm{ml})$, the risk of unexpected cardiovascular events was doubly increased. Only $10 \%$ of patients examined in the cohort study had $25(\mathrm{OH}) \mathrm{D}>75 \mathrm{nmol} / \mathrm{l}$ or $30 \mathrm{ng} / \mathrm{ml}[17,55]$.

Recent data (a meta-analysis of trials totalling 12000 participants) showed that calcium supplements (without coadministered Vit D) are associated with an increased risk of myocardial infarction by about 30\% [76].

It is now clear that a value of $25(\mathrm{OH}) \mathrm{D}$ of $75-100 \mathrm{nmol} / \mathrm{l}(30-40 \mathrm{ng} / \mathrm{ml})$ is optimal for both bone metabolism and extraskeletal manifestation. Insufficiency was determined at 25(OH)D 25-75 nmol/l (10-30 ng/ml) and deficiency at $25(\mathrm{OH}) \mathrm{D}<25 \mathrm{nmol} / \mathrm{l}(<10 \mathrm{ng} / \mathrm{ml})$. Complete deficiency leads to rickets in children and osteomalacia in adults $[7,56]$.

Also, studies of the health benefits of raising serum $25(\mathrm{OH}) \mathrm{D}$ levels to $100-112.5 \mathrm{nmol} / \mathrm{l}(40-45 \mathrm{ng} / \mathrm{ml})$ at the population level on the basis of serum 25(OH)D level-disease outcome responses estimate about a $15 \%$ reduction in the all-cause mortality rate and a reduction in the economic burden of disease treatment of 10-20\% [77, 78]. Another study estimated that if all those in the United States were to double their solar ultraviolet-B irradiance to raise their serum 25(OH)D level to $112.5 \mathrm{nmol} / \mathrm{l}(45 \mathrm{ng} / \mathrm{ml})$ the net result could be as many as 400,000 reduced deaths compared with only 11,000 increased deaths from melanoma and other skin cancer [79].

The Institute of Medicine (IOM) Committee concluded [65] that the evidence of Vit D or Ca reducing the risk of non-skeletal chronic disease outcomes was inconsistent, inconclusive, and did not meet criteria for establishing cause-and-effect relationships. Randomized trial evidence was sparse, and few trials assessed these outcomes as primary prespecified endpoints. Moreover, emerging evidence suggested a curvilinear or U-shaped curve for several outcomes related to Vit $D$, including cardiovascular disease, vascular calcification, falls, and frailty [56], with lower risk at moderate levels and increased risk at both low and high levels of 25(OH)D [65]. However, the data used to suggest that higher serum 25(OH)D levels are associated with adverse health outcomes for several types of cancer, CVD, and all cause an increased mortality rate, are inadequate representations of findings in the literature or are, essentially, taken out of context. When other findings are combined with those findings, one finds reduced disease rates with increasing Vit D indices [80] .

In the same report by the IOM Committee, based on bone health Recommended Dietary Allowances (RDAs; covering the requirements of $\geq 97.5 \%$ of the population), were given calcium intake ranging from 700 to $1300 \mathrm{mg} / \mathrm{d}$ for life-stage groups from 1 year of age. For Vit D, RDAs of $600 \mathrm{IU} / \mathrm{d}$ for ages 1-70 years and $800 \mathrm{IU} / \mathrm{d}$ for ages 71 years and older, corresponding to a serum 25 -hydroxyvitamin D level of at least $20 \mathrm{ng} / \mathrm{ml}(50 \mathrm{nmol} / \mathrm{l})$, meet the requirements of at least $97.5 \%$ of the population. The 2011 Vit D Dietary Reference Intakes (DRIs) are based primarily on the integration of bone health outcomes with evidence concerning $25(\mathrm{OH}) \mathrm{D}$ levels, which suggest that levels of $16 \mathrm{ng} / \mathrm{ml}(40 \mathrm{nmol} / \mathrm{l})$ meet the needs of approximately half the population, and levels of at least $20 \mathrm{ng} / \mathrm{ml}$ $(50 \mathrm{nmol} / \mathrm{l})$ meet the needs of at least $97.5 \%$ of the population (akin to the RDA). Intakes of Vitamin D required to achieve these $25(\mathrm{OH}) \mathrm{D}$ concentrations are based on a simulation of available data covering all ages under conditions of minimal sun exposure [65].

But, in the last "Comment on the IOM Vitamin D and Calcium Recommendations" by Heike BischoffFerrari and Walter Willett [74] the authors present 
the opinion that 25(OH)D levels far beyond $50 \mathrm{nmol} / \mathrm{l}(20 \mathrm{ng} / \mathrm{ml})$ in younger and older adults are needed for optimal bone health, suggesting that the IOM threshold recommendation is too low [81]. In contrast to the IOM report, the IOF recommended in their 2010 position paper on Vit D a threshold of $75 \mathrm{nmol} / \mathrm{l}$ for optimal fall and fracture reduction and recommended 800 to $1,000 \mathrm{IU}$ of Vit D per day for seniors aged 60 years and older $[82,83]$.

Further studies are necessary to define the relationship between atherosclerosis and OP with proved common risk factors including race and genetic and molecular determinants. The correlation between lipid profile and BMD was consistent neither at all bone sites, nor from study to study.

Existing evidence of extraskeletal Vit D outcomes from randomized clinical trials is limited and generally uninformative. Large randomized controlled trials and public health investigations are needed to reassess laboratory ranges for 25-hydroxyvitamin $D$ in both diseases, in order to avoid under- and overtreatment problems.

Education of clinicians and patients is one of the most important tasks in the prevention of atherosclerosis and osteoporosis. Raising awareness about maintaining a good quality of life will lead to a decrease in the risk of fractures, myocardial infarction and mortality. Consequently, additional studies are needed to determine the exact mechanisms shared by atherosclerosis and osteoporosis and clarify not only this relationship but also the underlying mechanism.

\section{References}

1. Danilevicius CF, Lopes JB, Pereira RM. Bone metabolism and vascular Calcification. Braz J Med Biol Res 2007; 40: 435-42.

2. Kiel DP, Kauppila LI, Cupples LA, Hannan MT, O'Donnell CJ, Wilson PW. Bone loss and the progression of abdominal aortic calcification over a 25 year period: the Framingham Heart Study. Calcif Tissue Int 2001; 68: 271-6.

3. Sinnott B, Syed I, Sevrukov A, Barengolts E. Coronary calcification and osteoporosis in men and postmenopausal women are independent processes associated with aging. Calcif Tissue Int 2006; 78: 195-202.

4. Von der Recke P, Hansen MA, Hassager C. The association between low bone mass at the menopause and cardiovascular mortality. Am J Med 1999; 106: 273-8.

5. Martins D, Wolf M, Pan D, et al. Prevalence of cardiovascular risk factors and the serum levels of 25-hydroxyvitamin D in the United States. Arch Intern Med 2007; 167: 1159-65.

6. Anagnostis P, Athyros VG, Adamidou F, Florentin M, Karagiannis A. Vitamin D and cardiovascular disease: a novel agent for reducing cardiovascular risk? Curr Vasc Pharmacol 2010; 8: 720-30.

7. Parhami F, Morrow AD, Balucan, et al. Lipid oxidation products have opposite effects on calcifying vascular cell and bone cell differentiation. A possible explanation for the paradox of arterial calcification in osteoporotic patients. Arterioscler Thromb Vasc Biol 1997; 17: 680-7.
8. Kendrick J, Targher G, Smits G, Chonchol M. 25-Hydroxyvitamin D deficiency is independently associated with cardiovascular disease in the Third National Health and Nutrition Examination Survey. Atherosclerosis 2009; 205: 255-60.

9. Montalcini T, Emanuele V, Ceravolo R, et al. Relation of low bone mineral density and carotid atherosclerosis in postmenopausal women. Am J Cardiology 2004; 94: 266-9.

10. Kanis J, McCloskey. Diagnosis of osteoporosis and assessment of fracture risk. In: Reginster JY, Rizzoli R (eds). Innovation in skeletal medicine. Elsevier 2008; 159-71.

11. Cooper C, Gehlbach S. Perspectives on the problem. In: Cooper C, Gehlbach S, Lindsay R (eds). Prevention and treatment of osteoporosis: a clinician's guide. Abingdon (UK) Taylor \& Francis 2005; 1-13.

12. Stone LK, Seeley GD, Lui Li-Yung, et al. BMD at multiple sites and risk of fracture of multiple types: long-term results from the study of osteoporotic fractures. J Bone Min Res 2003; 18: 1947-54.

13. Delmas P. The treatment of postmenopausal osteoporosis. In: Cooper C, Gehlbach S, Lindsay R (eds.). Prevention and treatment of osteoporosis: a clinician's guide. Abingdon (UK) Taylor \& Francis 2005; 57-81.

14. Ilić-Stojanović O, Popović G. Possible mistakes in the interpretation of bone densitometry measurements. Prevalence of vertebral fracture. Balneoclimatologia 2004; 28: 159-67.

15. Kanis JA, Burlet N, Cooper C, et al; European Society for Clinical and Economic Aspects of Osteoporosis and Osteoarthritis (ESCEO). European guidance for the diagnosis and management of osteoporosis in postmenopausal women. Osteoporos Int 2008; 19: 399-428.

16. Schulz E, Arfai K, Liu X, Sayre J, Gilsanz V. Aortic calcification and the risk of osteoporosis and fractures. J Clin Endocrinol Metab 2004; 89: 4246-53.

17. Bagger YZ, Tanko LB, Alexandersen P, Hansen HB, Qin G, Christiansen $\mathrm{C}$. Radiographic measure of aorta calcification is a site-specific predictor of bone loss and fracture risk at the hip. J Intern Med 2006; 259: 598-605.

18. Yamaguchi T, Sugimoto T, Yano S, et al. Plasma lipids and osteoporosis in postmenopausal women. Endocr J 2002; 49: 211-7.

19. Anagnostis P, Karagiannis A, Kakafika Al, Tziomalos K, Athyros VG, Mikhailidis DP. Atherosclerosis and osteoporosis: age-dependent degenerative processes or related entities? Osteoporos Int 2009; 20: 197-207.

20. Parhami F, Garfinkel A, Demer LL. Role of lipids in osteoporosis. Arterioscler Thromb Vasc Biol 2000; 20: 2346-348.

21. Orozco P. Atherogenic lipid profale and elevated lipoprotein (a) are associated with lower bone mineral density in early post-menopausal overweight women. Eur J Epidemiol 2004; 19: 1105-12.

22. Sivas F, Alemdaroğlu E, Elverici E, Kuluğ T, Ozoran K. Serum lipid profile: its relationship with osteoporotic vertebrae fractures and bone mineral density in Turkish postmenopausal women. Rheumatol Int 2009; 29: 885-90.

23. Solomon DH, Avorn J, Canning CF, Wang PS. Lipid levels and bone mineral density. Am J Med 2005; 118: 1414.

24. Adami S, BragaV, Zambolini M, et al. Relationship between lipids and bone mass in 2 cohorts of healthy women and men. Calcif Tissue 2004; 74: 136-42.

25. Brownbill RA, Ilich JZ. Lipid profile and bone paradox:higher serum lipids are associated with higher 
bone mineral density in postmenopausal women. J Womens Health (Larchmt) 2006; 15: 261-70.

26. Jeong IK, Cho SW, Kim SW, et al. Lipid profiles and bone mineral density in pre- and postmenopausal women in Korea. Calcif Tissue Int 2010; 87: 507-12.

27. Parhami F, Basseri B, Hwang J, Tintut Y, Demer LL. Highdensity lipoprotein regulates calcification of vascular cells. Circ Res 2002; 91: 570-6.

28. McFarlane SI, Muniyappa R, Shin JJ, Bahtiyar G, Sowers JR. Osteoporosis and cardiovascular disease: brittle bones and boned arteries, is there a link? Endocrine 2004; 23: 1-10.

29. Callister TQ, Raggi P, Cooil B, Lippolis NJ, Russo DJ. Effect of HMG-CoA reductase inhibitors on coronary artery disease as assessed by electron-beam computed tomography. N Engl J Med 1998; 339: 1972-8.

30. Mundy G, Garrett R, Harris S, et al. Stimulation of bone formation in vitro and in rodents by statins. Science 1999; 286: 1946-9.

31. Edwards CJ, Hart DJ, Spector TD. Oral statins and increased bone-mineral density in postmenopausal women. Lancet 2000; 355: 2218-9.

32. Meier CR, Schlienger RG, Kraenzlin ME, Schlegel B, Jick $H$. HMG-COA reductase inhibitors and the risk of fractures. JAMA 2000; 283: 3205-10.

33. Wang PS, Solomon DH, Mogun H, Avorn J. HMG-CoA reductase inhibitors and the risk of hip fractures in elderly patients. JAMA 2000; 283: 3211-6.

34. Chan KA, Andrade SE, Boles M, et al. Inhibitors of hydroxymethylglutaryl-coenzyme $A$ reductase and risk of fracture among older women. Lancet 2000; 355: 2185-8.

35. Adami S, Braga V, Guidi G, Gatti D, Gerardi DA, Fracassi E. Chronic intravenous aminobisphosphonate therapy increases high-density lipoprotein cholesterol and decreases low-density lipoprotein cholesterol. J Bone Min Res 2000; 15: 599-604.

36. Price PA, Faus SA, Williamson MK. Bisphosphonates alendronate and ibandronate inhibit artery calcification at doses comparable to those that inhibit bone resorption. Arterioscler Thromb Vasc Biol 2001; 21: 817-24.

37. Luckman SP, Hughes DE, Coxon FP, Graham R, Russell G, Rogers MJ. Nitrogen-containing bisphosphonates inhibit the mevalonate pathway and prevent post-translational prenylation of GTP-binding proteins, including Ras. J Bone Miner Res 1998; 13: 581-9.

38. Shimshi M, Abe E, Fisher EA, Zaidi M, Fallon JT. Bisphosphonates induce inflammation and rupture of atherosclerotic plaques in apolipoprotein-E null mice. Biochem Biophys Res Commun 2005; 328: 790-3.

39. Abedin M, Tintut Y, Demer LL. Vascular calcification: mechanisms and clinical ramifications. Arterioscler ThrombVasc Biol 2004; 24: 1161-70.

40. Baldini V, Mastropasqua M, Francucci CM, D’Erasmo E. Cardiovascular disease and osteoporosis. J Endocrinol Invest 2005; 28: 69-72.

41. Tanaka S, Haji M, Takayanagi R, Sugioka Y, Nawata H. 1,25dihydroxyvitamin D3 enhances the enzimatic activity and expression of the messenger ribonucleic acid for aromatase cytochrome P450 synergistically with dexamethasone depending on the vitamin $D$ receptor level in cultured human osteoblasts. Endocrinology 1996; 137: 1860-9.

42. Hughes SV, Robinson E, Bland R, Lewis HM, Stewart M, Hewison M. 1,25-dihidroxyvitamin D3 regulates estrogen metabolism in cultured keratinocites. Endocrinology 1997; 138: $3711-8$
43. Christiansen C, Lindsay R. Estrogen, bone loss and preservation.Osteoporos Int 1990; 1: 7-13.

44. Mendelsohn ME, Karas RH. The protective effects of estrogen on the cardiovascular system. N Engl J Med 1999; 340: 1801-1.

45. Christen WG, Ajani UA, Glynn RJ, et al. Blood levels of homocysteine and increaseD risks of cardiovascular disease:causal or casual? Arch Intern Med 2000; 160: 422-34.

46. MiyaoM, Morita H, Hosoi Tetal. Association of methylenetetrahydrofolate reductase (MTHFR) polymorphism with bone mineral density in postmenopausal Japanese women. Calcif Tissue Int 2000; 66: 190-4.

47. Askim M. Vitamin $K$ in the Norwegian diet and osteoporosis. Tidsskr Nor Laegeforen 2001; 121: 2614-6.

48. Iwamoto J, Takeda T, Sato Y. Effects of vitamin K2 on osteoporosis. Curr Pharm Des 2004; 10: 2557-76.

49. Iwamoto J, Takeda T, Sato Y. Role of vitamin K2 in the treatment of postmenopausal osteoporosis. Curr Drug Saf 2006; 1: 87-97.

50. Vermeer C, Shearer MJ, Zittermann A, et al. Beyond deficiency: potential benefits of increased intakes of vitamin $\mathrm{K}$ for bone and vascular health. Eur J Nutr 2004; 43: 325-35.

51. Shoji S. Vitamin K and vascular calcification. Clin Calcium 2002; 12: 1123-8.

52. Schurgers LJ, Dissel PE, Spronk HM, et al. Role of vitamin K and vitamin $\mathrm{K}$ dependent proteins in vascular calcification. Z Kardiol 2001; 90 Suppl 3: 57-63.

53. Anagnostis P, Athyros VG, Adamidou F, Florentin M, Karagiannis A. Vitamin $D$ and cardiovascular disease: a novel agent for reducing cardiovascular risk? Curr Vasc Pharmacol 2010; 8: 720-30.

54. Holick MF. Vitamin D status: measurement, interpretation and clinical application. Ann Epidemiol 2009; 19: 73-8.

55. DeLuca HF. Overview of general psysiologic features and functions of vitamin D. Am J Clin Nutr 2004; 80: 1689-96.

56. Wang T, Pencina M, Booth S, et al. Vitamin D deficiency and risc of cardiovascular disease. Circulation 2008; 117: 503-11.

57. Zittermann A, Schleithoff SS, Koerfer R. Vitamin D and vascular calcification. Curr Opin Lipidol 2007; 18: 41-6.

58. de Boer IH, Kestenbaum B, Shoben AB, Michos ED, Sarnak MJ, Siscovick DS. 25-hydroxyvitamin D levels inversely associate with risk for developing coronary artery calcification. J Am Soc Nephrol 2009; 20: 1805-12.

59. Lips P. Vitamin D deficiency and secondary hyperparathyroidism in the elderly: consequences for bone loss and fractures and therapeutic implications. Endocr Rev 2001; 22: 477-501.

60. Li YC, Kong J, Wei M, Chen ZF, Liu SQ, Cao LP. 1,25Dihydroxyvitamin D3 is a negative endocrine regulator of the renin-angiotensin system. J Clin Invest 2002; 110: 229-38.

61. Zittermann A. Vitamin D and disease prevention with special reference to cardiovascular disease. Prog Biophys Mol Biol 2006; 92: 39-48.

62. Sambrook PN, Chen CJ, March L, et al. High bone turnover is an independent predictor of mortality in the frail elderly. J Bone Miner Res 2006; 21: 549-55.

63. Kuhlencordt PJ, Gyurko R, Han F, et al. Accelerated atherosclerosis, aortic aneurysm formation, and ischemic heart disease in apolipoprotein E/endothelial nitric oxide synthase double-knockout mice. Circulation 2001; 104: 448-54.

64. Roux C, Bischoff-Ferari HA, Papapoulos SE, et al. New insight into the role of vitamin DD and calcium in 
osteoporosis management: an expert roundtable discussion. Curr Med Res Opin 2008; 24: 1363-70.

65. Ross AC, Manson JE, Abrams SA, et al. The 2011 Report on dietary reference intakes for calcium and vitamin $D$ from the Institute of Medicine: what clinicians need to know. J Clin Endocrinol Metab 2011; 96: 53-8.

66. Hathcock JN, Shao A, Vieth R, Heaney R. Risk assessment for vitamin D. Am J Clin Nutr 2007; 85: 6-18.

67. Vieth R, Bischoff-Ferrari H, Boucher B, Dawson-Hughes B, Garland $C$. The urgent need to recommend an intake of vitamin D that is effective. Am J Clin Nutr 2007; 85: 649-50.

68. Theiler R, Stahelin HB, Kranzlin M, et al. Influence of physical mobility and season on 25-hydroxyvitamin D-parathyroid hormone interaction and bone remodelling in the elderly. Eur J Endocrinol 2000; 143: 673-9.

69. Bischoff-Ferrari HA, Giovannucci E, Willett WC, Dietrich T, Dawson-Hughes B. Estimation of optimal serum concentrations of 25-hydroxyvitamin D for multiple health outcomes. Am J Clin Nutr 2006; 84: 18-28.

70. Cranney A, Horsley T, O'Donnell S, et al. Effectiveness and safety of vitamin D in relation to bone health. Evid Rep Technol Assess (Full Rep) 2007; 158: 1-235.

71. Bischoff-Ferrari HA, Dawson-Hughes B. Where do we stand on vitamin D? Bone 2007; 41: 13-9.

72. Bischoff-Ferrari HA, Dawson-Hughes B, Baron JA, et al. Calcium intake and hip fracture risk in men and women: a meta-analysis of prospective cohort studies and randomized controlled trials. Am J Clin Nutr 2007; 86: 1780-90.

73. Bischoff-Ferrari HA, Kiel DP, Dawson-Hughes B, et al. Dietary calcium and serum 25 -hydroxyvitamin D status in relation to BMD among U.S. adults. J Bone Miner Res 2009; 24: 935-42.

74. Bischoff-Ferrari H, Willett W. Comment on the IOM Vitamin D and Calcium Recommendations.The Nutrition Source, Harvard School of public Health. Available at: (http://www.hsph.harvard.edu/nutritionsource/whatshould-you-eat/vitamin-d-fracture-prevention/.

75. Garnero P, Munoz F, Sornay-Rendub E, Delmas D. Associations of vitamin $D$ status with bone mineral density, bone turnover, bone loss and fracture risk in healthy postmenopausal women. The OFELY study. Bone 2007; 716-22.

76. Bolland MJ, Avenell A, Baron JA, et al. Effect of calcium supplements on risk of myocardial infarction and cardiovascular events: meta-analysis. BMJ 2010; 341: c3691.

77. Grant WB, Cross HS, Garland CF, et al. Estimated benefit of increased vitamin D status in reducing the economic burden of disease in western Europe. Prog Biophys Mol Biol 2009; 99: 104-13.

78. Grant WB, Schwalfenberg GK, Genuis SJ, Whiting SJ. An estimate of the economic burden and premature deaths due to vitamin D deficiency in Canada. Molec Nutr Food Res 2010; 54: 1172-81.

79. Grant WB. In defense of the sun: an estimate of changes in mortality rates in the United States if mean serum 25 -hydroxyvitamin D levels were raised to $45 \mathrm{ng} / \mathrm{mL}$ by solar ultraviolet-B irradiance. Dermatoendocrinology 2009; 1: 207-14.

80. Grant WB. Critique of the U-shaped serum 25-hydroxyvitamin D level-disease response relation. Dermatoendocrinology 2009; 1: 1-5.

81. Bischoff-Ferrari HA, Dietrich T, Orav EJ, DawsonHughes B. Positive association between 25-hydroxy vitamin $\mathrm{D}$ levels and bone mineral density: a population- based study of younger and older adults. Am J Med 2004; 116: 634-9.

82. Bischoff-Ferrari HA, Dawson-Hughes B, Staehelin HB, et al. Fall prevention with supplemental and active forms of vitamin D: a meta-analysis of randomised controlled trials. Br Med J 2009; 339: b3692.

83. Dawson-Hughes B, Mithal A, Bonjour JP, et al. IOF position statement: vitamin $D$ recommendations for older adults. Osteoporosis Int 2010; 21: 1151-4. 